\title{
Novo ensino médio: uma busca pelos alicerces em tempos de reestruturação curricular
}

\author{
New high school: a search for foundations in time of curriculum \\ restructuring
}

\author{
Ellen Maianne Santos Melo \\ Professora doutoranda do Instituto Federal de Alagoas, Maceió, AL, Brasil. \\ ellen.melo@ifal.edu.br - https://orcid.org/0000-0002-8051-265X

\section{Walter Matias Lima} \\ Professor doutor da Universidade Federal de Alagoas, Maceió, AL, Brasil. \\ waltermatias@gmail.com - https://orcid.org/0000-0001-7331-9475
}

Recebido em 30 de agosto de 2021

Aprovado em 13 de outubro de 2021

Publicado em 30 de dezembro de 2021

RESUMO: Este trabalho pretende responder a seguinte questão: sob quais alicerces devem se desenvolver a educação em tempos de reestruturação curricular? Conforme este problema central, objetivamos: apresentar as principais mudanças constantes nos documentos que legislam sobre a reformulação da educação em nosso país e apresentar uma defesa da importância das fronteiras disciplinares. Como referencial teórico para o desenvolvimento do trabalho foi utilizado Hannah Arendt, em: A crise na educação; Terry Shinn, em: Regimes de produção e difusão de ciência: rumo a uma organização transversal do conhecimento, Ronai Rocha: Quando ninguém educa: questionando Paulo Freire e Ensino de Filosofia e Currículo. Como base teórica sobre estudo de teoria curricular, utilizamos André Chervel: História das disciplinas escolares e Michael Young: Conhecimento e Currículo. Defendemos que a escola, para que cumpra seu papel de educar, não deve abrir mão de ensinar. E, como o que ensina e quem ensina, deve ensinar algo, os alicerces sob os quais devem se construir o ato educativo, denominam-se componentes curriculares ou disciplinas.

Palavras-chave: novo ensino médio; currículo; conservação.

\begin{abstract}
This paper intends to answer the following question: on what basis should education be developed in times of curricular restructuring? According to this central problem, we aim to present the main changes in the documents that legislate on the reformulation of education in our country and to present a defense of the importance of disciplinary boundaries. As a theoretical reference for the development of the work, it was used: Hannah Arendt, in: The crisis in education; Terry Shinn, in: Science production and diffusion regimes: towards a transversal organization of knowledge, Ronai Rocha: When no one educates, questioning Paulo Freire and Teaching Philosophy and Curriculum. As a theoretical basis on the study of curricular theory, we used André Chervel: History of school subjects and Michael Young: Knowledge and Curriculum. We defend that the school, to fulfill its role of educating, should not give up teaching. And, as the one who teaches and the one who teaches, must teach something, the foundations on which the educational act must be built, are called curricular components or disciplines.
\end{abstract}

Keywords: new high school; curriculum; conservation. 


\section{O novo ensino médio e a queda dos alicerces}

Os alicerces da educação brasileira foram profundamente abalados, segundo um conjunto de documentos legais produzidos no Brasil, a partir de 2016 - após a deposição da Presidenta eleita - que reconfiguram o ensino médio brasileiro. Utilizamos essa metáfora arquitetônica de queda dos alicerces porque pensamos que ela consegue traduzir a concepção do novo ensino médio, uma vez que com a nova legislação, o currículo deste nível de ensino é profundamente alterado e o modelo disciplinar é desincentivado.

Dentre os documentos que legislam sobre o novo ensino médio, estão: a Lei. 13.415, aprovada em fevereiro de 2017; a Base Nacional Comum Curricular - BNCC, aprovada, uma parte em 2017 e outra parte em dezembro de 2018; as Diretrizes Curriculares Nacionais para o Ensino Médio - DCNEM, aprovada em novembro de 2018 e Base Nacional Comum para a Formação de professores da Educação Básica - BNC Formação, aprovada em dezembro de 2019.

Essa base legal citada acima legisla sobre a reformulação da educação ofertada em todos os níveis de ensino no Brasil: da educação infantil ao ensino superior. No entanto, este trabalho se aterá em abordar mais especificamente, as mudanças preconizadas para o ensino médio.

O novo ensino médio proposto pelo governo, em consulta pública aberta na página do Senado Federal, recebeu 73.565 não e apenas 4.551 sim para a pergunta: "Você apoia essa proposição?"1 Mas, mesmo diante da rejeição da proposta por grande parcela da sociedade, sinalizadas a partir do movimento de ocupações das escolas - ocorrido em 2016 - e da aferição da opinião popular por meio de pesquisas de opinião, o governo transforma a Medida Provisória $n^{\circ} 746$ na Lei 13.415, no dia 8 de fevereiro de 2017, reestruturando todo o ensino médio brasileiro, apenas 147 dias depois da publicação da MP.

A reconfiguração do ensino médio é expressa mais diretamente na Lei $n^{\circ}$ 13.415/2017, pois ela remodela cinco artigos importantes (art. 24; 36; 44; 61 e 62) da Lei de Diretrizes e Bases da Educação Nacional (LDB - Lei 9394/96) e introduz 
um novo (art. 35-A). Esses artigos citados, em linhas gerais, provocam as seguintes mudanças: retira a concepção de que a educação brasileira deva fortalecer a formação humana integral; interfere na formação e atuação dos profissionais da educação e, desta forma, irrompe também na autonomia pedagógica das unidades escolares.

As mudanças expressas nos artigos citados acima ampliam ao mesmo tempo em que desintegra os espaços e tempos escolares. Amplia, uma vez que aumenta a carga horária de 800 para 1400 horas anuais e institui o ensino integral. Desintegra o currículo ao promover a desestruturação curricular, quando institui que o currículo será constituído por dois blocos: a BNCC e os Itinerários Formativos.

A instauração da BNCC e dos Itinerários Formativos não preconizam a manutenção de um currículo centrado por um modelo disciplinar; mas, ao contrário, desincentiva a manutenção deste modelo, ao estabelecer no Artigo 35 - A da LDB (alterada pela Lei 13.415/17) e no Artigo 36, que o currículo do ensino médio deverá ser organizado por áreas do conhecimento - tanto na parte da BNCC, quanto nos Itinerários Formativos. E, a partir destas áreas são apresentadas na BNCC as habilidades e competências correspondentes a cada área.

Desta forma, vemos se desenhar a diluição das disciplinas nas suas respectivas áreas do saber, uma vez que não é garantida pela nova legislação educacional a permanência delas no currículo. Entende-se que apenas Língua Portuguesa e Matemática têm os seus lugares garantidos na legislação, tendo o direito de permanecer enquanto disciplinas, uma vez que elas caracterizam as áreas de Linguagem e suas tecnologias e Matemática e suas tecnologias.

\section{A nova composição do currículo do ensino médio}

No artigo $36^{\circ}$ da Lei $n^{\circ} 13.415 / 2017$ é apresentada a nova composição do currículo do Ensino Médio:

O currículo do ensino médio será composto pela Base Nacional Comum Curricular e por itinerários formativos, que deverão ser organizados por meio da oferta de diferentes arranjos curriculares, conforme a relevância para o contexto local e a possibilidade dos sistemas de ensino - Grifo nosso (BRASIL, Lei n 13.415/2017). 
Da forma como está descrito acima, os alicerces educacionais do ensino médio são derrubados, pois se relativiza o currículo escolar, retirando as bases gerais que são os componentes curriculares sobre os quais devem se assentar a educação. Embora se fale em BNCC enquanto uma base comum curricular, a BNCC do ensino médio não apresenta quais serão os componentes curriculares que comporão a base comum curricular - com exceção apenas, de língua portuguesa e matemática. Ao contrário da BNCC do ensino fundamental, onde são apresentadas as cinco áreas de estudos e os nove componentes curriculares a serem estudados. Assim, a base comum curricular do ensino médio não se apresenta como uma base comum, pois nela está ausente qualquer modelo, referência ou padrão, porque nem ao menos cita os componentes curriculares indispensáveis para a formação dos estudantes, mas, os dilui em suas respectivas áreas.

A BNCC assevera que "cabe aos sistemas e às escolas adotar a organização curricular que melhor responda aos seus contextos e suas condições: áreas, interáreas, componentes, projetos, centros de interesse e etc" (p. 471). Ao proporcionar diferentes arranjos curriculares, renunciando-se aos componentes curriculares tradicionais, a escola deixa de fornecer o chão necessário sob o qual deve estar assentada a flexibilização dos currículos. De acordo com Chervel (1990), são as disciplinas que traduzem a função da escola. Diz ele:

A função da escola é instruir e criar disciplinas que são um vasto conjunto cultural, amplamente original que ela secretou ao longo de decênios ou séculos e que funciona como uma mediação post a serviço da juventude escolar em sua lenta progressão em direção à cultura da sociedade global (CHERVEL,1990, p. 200).

Chervel, no livro A história das disciplinas escolares, partindo do método histórico do estudo que busca saber a história das disciplinas escolares, defende que as disciplinas são aquilo que se ensina nas escolas e que elas surgem lentamente como,

fruto de um diálogo secular entre os mestres e os alunos, elas constituem por assim dizer o código que duas gerações, lentamente, minuciosamente, elaboraram em conjunto para permitir a uma delas transmitir à outra uma cultura determinada (CHERVEL,1990, p. 222). 
Para Chervel (1990), o que define a modalidade do conhecimento escolar são os conteúdos das disciplinas (p. 203). É possível ver a partir de Chervel a defesa da importância das disciplinas como transmissoras de conhecimentos e cultura que trabalham pela perenização da sociedade (p. 222). E que a presença das disciplinas nos currículos escolares goza de grande estabilidade. Chervel (1990) analisando mais especificamente a realidade francesa, afirma que "As diferentes matérias que estão atualmente em vigor no ensino secundário são, já se viu, correntemente designadas como "disciplinas" desde a primeira Guerra Mundial, aproximadamente" (p. 213).

Contudo, o que vemos na nova legislação educacional do nível médio é a falta de esclarecimentos e definições curriculares. Assim, grandes expectativas se tinham que a BNCC conseguisse clarificar os novos caminhos da educação no nível de ensino médio. Como seria o arranjo curricular? Que disciplinas seriam obrigatórias? Quais seriam dispensadas? Como as escolas se organizarão? No entanto, muitas dessas respostas ainda continuaram vagas com a homologação e publicação da BNCC, que se deu quase dois anos após a promulgação da Lei da 13.415/17.

De acordo com o transcrito do texto da própria BNCC,

A BNCC não se constitui no currículo dessa etapa, mas define as aprendizagens essenciais a ser garantidas a todos os estudantes e orienta a (re)elaboração de currículos e propostas pedagógicas (...). Na direção de substituir o modelo único de currículo do Ensino Médio por um modelo diversificado e flexível, a Lei $n^{\circ} 13.415 / 2017$ alterou a LDB. (...) Essa nova estrutura valoriza o protagonismo juvenil, uma vez que prevê a oferta de variados itinerários formativos para atender à multiplicidade de interesses dos estudantes: o aprofundamento acadêmico e a formação técnica profissional. Além disso, ratifica a organização do Ensino Médio por áreas do conhecimento, sem referência direta a todos os componentes que tradicionalmente compõem o currículo dessa etapa. - Grifo nosso (BRASIL, BNCC, p. 467).

Assim, vemos que os componentes curriculares se diluem nas áreas do saber, ao não se especificar os componentes curriculares que devem constar no currículo do ensino médio, mesmo que estivessem dispostos através das suas respectivas áreas. A partir disso, não há garantias de que sejam ofertados aos (as) 
estudantes de ensino médio o acesso aos conhecimentos discriminados a partir dos mais diversos componentes curriculares que compõem cada área do saber. Com isso, pode haver uma diminuição da oferta de componentes curriculares e diminuição do tratamento dos seus ricos assuntos.

Embora antes das mudanças preconizadas para o novo ensino médio, a LDB não especificasse todas as disciplinas ou componentes curriculares que deveriam constar no currículo, no texto anterior às mudanças implementadas pela Lei 13.415/17, eram citadas diversos nomes de disciplinas ou componentes curriculares que deveriam, obrigatoriamente, fazer parte do currículo, tais como: Filosofia e Sociologia (artigo $36^{\circ}$, inciso IV - revogado); Artes (artigo $24^{\circ}$, inciso IV); História do Brasil (art. $26^{\circ} \S 4^{\circ}$ ); Língua estrangeira (art. 26, $\S 5^{\circ}$ ) e Educação Física (art. 26, $\S$ $\left.3^{\circ}\right)$.

Mas, ao revogar o antigo artigo $36^{\circ}$ que dizia que para compor o currículo do ensino médio deveria observar o disposto nas diretrizes da seção I do Capítulo II da LDB, deixa de ser preponderante, para compor o currículo do novo ensino médio, observar o que está disposto na seção I do Capítulo II, que compreende os artigos do 22 ao 27. Desta forma, além de deixar de citar a obrigatoriedade dos componentes curriculares citados acima, a revogação do antigo artigo $36^{\circ}$ invalida as diretrizes que preconizavam que o currículo do ensino médio destacaria "a educação tecnológica básica, a compreensão do significado da ciência, das letras e das artes; o processo histórico de transformação da sociedade e da cultura, a língua portuguesa como instrumento de comunicação, acesso ao conhecimento e exercício da cidadania" (Artigo 36, revogado).

A redação anterior do artigo $36^{\circ}$, ao se referir ao disposto na Seção I do capítulo II, como diretrizes a serem seguidas, trazia mais detalhes (especificações) ao currículo do ensino médio, pois além de citar diversos componentes curriculares obrigatórios, segundo a citação acima, ainda indicava a necessidade do ensino de História, Linguagens, Artes e Letramento Científico, além da Língua portuguesa e ressalta a necessidade da preparação para o exercício da cidadania. Mas, o novo artigo $36^{\circ}$ institui que o currículo do ensino médio deverá ser composto pela Base 
Nacional Comum Curricular e por Itinerários Formativos e apresentam por áreas a composição do novo currículo do ensino médio.

As aprendizagens essenciais não são definidas pela nova legislação, nem são citados os componentes curriculares indispensáveis à formação dos estudantes. Embora o conteúdo da BNCC citado acima afirme que ela definirá as aprendizagens essenciais para orientar a reelaboração dos currículos, isso não ocorre de fato. Porém, se a BNCC não traz uma base comum, nem define as aprendizagens essenciais, então, do que se tratam as mais de 100 páginas da BNCC do ensino médio? Ela trata vagamente sobre as habilidades e competências a serem desenvolvidas pelos estudantes em cada uma das quatro áreas de saber - deixando de fora o ensino técnico e profissional - sem se referir de forma específica, a nenhuma disciplina ou componentes curriculares.

Como explicação para isso, justificam que "é preciso romper com a centralidade das disciplinas nos currículos e substituí-las por aspectos mais globalizadores e que abranjam a complexidade das relações existentes entre os ramos da ciência no mundo real” (BRASIL, BNCC, p. 471).

Ao não definir os conhecimentos essenciais sob a forma de conteúdos e componentes curriculares, a prioridade escolar de focar no conhecimento em si dá lugar a prioridade no enfoque do conhecimento para fazer algo. Conforme Macedo (2016), o conhecimento em si e conhecimento para fazer algo são duas ideias que se antagonizam nas discussões sobre base curricular comum no Brasil. Para ela: "A prevalência dos currículos disciplinares, que se propõe a mimetizar na escola os campos científicos com maior ou menor consciência dos processos de recontextualização, indica a importância do conhecimento em si” (p. 55).

No caso da reformulação do ensino médio brasileiro, o foco está no conhecimento para fazer algo, pois as mudanças curriculares estabelecem itinerários formativos específicos, ao mesmo tempo em que não especifica qual será a base comum dos currículos. Ao invés de componentes curriculares e conteúdos, temos, ao longo do texto da BNCC, a descrição de competências e habilidades distribuídas por área do saber. 
A BNCC reflete uma penúria conceitual e traduz o quanto a prática curricular brasileira promove um esvaziamento do sentido da educação e do papel da escola. Este documento divide a apresentação do que chamam de direitos e objetivos de aprendizagens, em quatro áreas: Linguagens e suas tecnologias; Matemática e suas tecnologias; Ciências da Natureza e suas tecnologias e Ciências Humanas e Sociais aplicadas. No total, são apresentadas 21 competências e 183 habilidades que os estudantes devem desenvolver. Mas, ao menos cuidam de conceituar e fundamentar epistemologicamente o que chamam de competências e habilidades.

Essas competências e habilidades são distribuídas pelas áreas de forma bastante desigual e demonstram que existem áreas com didática mais consolidadas pela tradição, enquanto existem outras que carecem de mais pesquisa para consolidar seu campo didático. Desta forma, a área de Linguagens (língua portuguesa, língua estrangeira, artes e educação física) apresenta 81 habilidades para serem desenvolvidas pelos estudantes, enquanto a área de Ciências da Natureza (química, física e biologia) apresenta apenas 26 habilidades. A área da Matemática, composta apenas por matemática, apresenta 43 habilidades. E a área de Ciências Humanas (história, geografia, filosofia e sociologia) apresenta 32 habilidades. Mas, por que tamanha discrepância e desigualdade na definição das habilidades a serem desenvolvidas por cada área? Algumas áreas seriam mais relevantes do que outras? Em momento algum da BNCC há qualquer esclarecimento a respeito desta desigualdade de apresentação do conteúdo de cada área.

De acordo com Rocha (2017),

É desigual, pois as comunidades de especialistas de cada disciplina estão em níveis muito diferentes de elaboração conceitual, uns apenas começando, outros com décadas de estrada. É descombinada porque não há um quadro de referência teórico mais amplo, nem minimamente partilhado que pudesse gerar um efeito mínimo de atualização dos esforços das comunidades de especialistas (ROCHA, 2017, p. 145).

A desigualdade de apresentação da distribuição das habilidades e competências por área é visível quando observamos a distinção da linguagem empregada para descrever as habilidades e competências de cada área e a 
utilização de distintos termos para significar ideias semelhantes. Assim, para apresentar a divisão das habilidades e competências, a área de Linguagens decide chamar a divisão de campos de atuação (social; artístico; pesquisa; jornalístico e atuação pública). Já a área de Matemática chama a divisão de unidades (números e álgebra; geometria e medidas e estatística). As Ciências Humanas estão divididas em categorias (tempo e espaço; território e fronteira; indivíduo, natureza, sociedade, cultura e ética e política e trabalho). Por fim, a área de Ciências da Natureza está dividida em temáticas (matéria e energia; vida e evolução e terra e universo).

O conteúdo da BNCC traduz que não há um diálogo entre as áreas do saber. Ela parece ter sido escrita por grupos de especialistas, isoladamente, sem ter uma discussão sobre integração ou o estabelecimento de acordos conceituais entre os grupos das diferentes áreas do saber. O livro "A BNCC na contramão do PNE" denuncia que não houve uma discussão aprofundada para a consolidação da versão final do documento, pois se deu prioridade à celeridade do processo (DOURADO, 2018). As autoras denunciam também "que houve uma construção linear, vertical e centralizadora" da versão final e que a BNCC foi elaborada de forma autônoma pelo comitê gestor, pois foi este que definiu quais contribuições da apreciação pública seriam atendidas (Idem, p. 16).

Esta falta de discussão aprofundada sobre teoria curricular e epistemologia para se construir este importante documento é evidenciado por um vazio conceitual que empobrece a proposta de educação exposta na BNCC, pois não é evidenciado o valor formativo do ensino médio. Embora a BNCC fale basicamente de competências e habilidades, não é dedicada nenhuma página para explanar e fundamentar o conceito de competências, nem de habilidades. Em apenas um parágrafo das 600 páginas do documento, encontramos uma tentativa piedosa de conceituação do termo competências: "Na BNCC, competência é definida como a mobilização de conhecimentos (conceitos e procedimentos), habilidades (práticas, cognitivas e socioemocionais), atitudes e valores para resolver demandas complexas da vida cotidiana, do pleno exercício da cidadania" (BRASIL, BNCC, p. 8). 
Por conseguinte, entendemos que a ideia de competências exposta na BNCC, quer expressar o nível de performance - desempenho, esperado dos estudantes, ao demonstrarem serem capazes de executar determinadas ações. Por isso, as competências são sempre apresentadas com verbos no infinitivo, como, por exemplo: investigar, apreciar, propor etc. Mas, desta forma, a educação tem o seu valor formativo menosprezado, uma vez que o papel da escola não é mais proporcionar conhecimentos, mas apenas suscitar o despertar das habilidades e competências. O foco está no comportamento, não no conhecimento e por conta disto não há uma ocupação com a necessidade de conteúdos e conhecimentos, nem mesmo há uma ocupação em citar os componentes curriculares que deverão compor o currículo. Macedo (2016), citando Lyotard (1998), afirma que a educação separada de seu valor formativo, torna-se operacional e passa a ser legitimada por sua capacidade de otimizar performances (p. 57). Essa tendência pelo conhecimento para fazer algo é fruto do gerencialismo neoliberal que pretende fornecer "ao sistema jogadores capazes de assegurar convenientemente seu papel junto aos postos pragmáticos de que necessitam as instituições" (LABAREE, 1998, p. 89).

Essa pragmaticidade da educação preconizada pelo novo ensino médio é visível a partir do esvaziamento dos direitos de aprendizado dos estudantes. Oferecemos como exemplo do esvaziamento dos direitos de aprendizado dos estudantes o que está disposto na BNCC, na área de ciências naturais. Esta área representa o empobrecimento do valor educativo, mais piedoso entre todas as áreas. Toda área que deveria compreender os conhecimentos de química, física e biologia é apresentada dividida em três temáticas: matéria e energia; vida e evolução e terra e universo. A partir destas três temáticas são apresentadas as três competências definidas para a área. A competência número um, insere a temática matéria e energia. Mas as temáticas, vida e evolução e terra e universo se fundem em uma única competência: "Analisar e utilizar interpretações sobre a dinâmica da Vida, da Terra e do Cosmos para elaborar argumentos, realizar previsões sobre o funcionamento e a evolução dos seres vivos e do Universo, e fundamentar e defender decisões éticas e responsáveis" (BRASIL, BNCC, p. 553). E, a terceira e 
última competência é: investigar situações problemas, utilizando procedimento e linguagens das ciências da natureza e propor soluções por meio de tecnologias. Nestas três competências impostas para a área de ciências naturais, bem como nas 26 habilidades, os conhecimentos de biologia, e mais ainda, os conhecimentos e conteúdos disciplinares cabíveis à Física e à Química estão praticamente invisíveis, como: ligações químicas, números quânticos, movimento, força e muitos outros assuntos importantes para a formação dos jovens.

Desta forma, vemos que a BNCC promove uma derrubada dos alicerces tradicionais que fundamentavam o currículo do ensino médio, por não apresentar os direitos de aprendizagens dos estudantes, prejudicando assim o desenvolvimento de uma prática pedagógica que preze pelo desenvolvimento de uma educação pautada no ensino de conhecimentos e conteúdos disciplinares.

O extravio curricular que derruba os alicerces da educação em nosso país é exposto também em documentos como as DCNEM. Na conceituação de currículo constante no capítulo I, que fala sobre a organização curricular, tem-se: "o currículo é conceituado como a proposta de ação educativa constituída pela seleção de conhecimentos construídos pela sociedade (...)." (art. $7^{\circ}$ ). Vemos que o conceito chave que dá sentido à ação educativa é conhecimento. Mas, a ideia de conhecimento é sempre provida da ideia de conteúdo. Afinal, conhecimento é sempre o conhecimento de algo. No entanto, a materialidade desses conhecimentos não aparece enquanto conteúdo, pois se fala apenas de habilidades e competências.

Conforme o novo ensino médio, as treze disciplinas tradicionais que compõem o atual ensino médio não precisam ser mantidas. O artigo 11, das DCNEM, especifica que a formação geral básica, na verdade, não tem nada de geral, nem básica: "a formação geral básica é composta por competências e habilidades previstas na BNCC". Logo em seguida, afirma que essa formação geral básica deverá ser organizada por áreas de conhecimentos, citando, assim, nos incisos as quatro áreas do saber. O disposto no artigo 11, das DCNEM, deixa bem claro que: "o currículo por área de conhecimento deve ser organizado e planejado dentro das áreas de forma interdisciplinar e transdisciplinar". Fica claro, assim, que 
mesmo a parte do currículo chamada de Formação Geral Básica será vulnerável e adaptável, pois também estará dividida por áreas e não está garantida a permanência de disciplinas. Mesmo assim é preconizado que o currículo será organizado de forma interdisciplinar e transdisciplinar. No entanto, como haver a inter e transdisciplinaridade sem a existência das disciplinas? É uma pergunta que fica sem resposta, se levarmos em consideração o conteúdo da legislação do novo ensino médio.

Vimos, então, conforme o exposto acima, que a destruição dos alicerces educativos do ensino médio é constatada no conteúdo da Lei 13.415/17, na BNCC e nos DCNEM, uma vez que eles não preconizam a manutenção de um currículo disciplinar composto por componentes distintos e que façam parte de uma matriz de conhecimentos básicos para todo o território nacional. O que vimos através destes documentos que legislam sobre o novo ensino médio é o esvaziamento do sentido da educação e da escola ao se desconsiderar a importância das disciplinas e dos seus respectivos assuntos.

\title{
As fronteiras disciplinares
}

O novo ensino médio proporciona o empobrecimento dos conhecimentos disciplinares, ao desconsiderar as especificidades de cada componente curricular. As disciplinas devem ser as bases do conhecimento epistemológica e ponto de referência para qualquer proposta de arranjo curricular que se queira implementar, seja ela por meio de problemas, projetos ou por disciplinas.

\begin{abstract}
As disciplinas escolares materializam o esforço de apresentação e entrega daquilo que há de valioso no que se refere a habilidades, conhecimentos e familiaridades sobre o mundo material, formal e espiritual. Como podemos fazer essa entrega? Não existe um modo canônico para a transmissão do legado de realizações à nova geração. A forma predominante consiste na apresentação dos conteúdos específicos de cada uma das disciplinas alocadas no currículo (ROCHA, 2017, p. 97).
\end{abstract}

De acordo com Rocha (2017), qualquer discussão sobre o currículo deve levar em conta uma discussão sobre epistemologia, conversando longamente sobre 
a natureza dos conhecimentos. É necessário discutir sobre o papel dessas disciplinas no crescimento e na formação humana, para daí definir, através de um critério epistemológico, a hierarquia de ocupação dos tempos e espaços dentro de um currículo.

Rocha (2017) defende que para se falar de currículo, precisamos falar primeiro de epistemologia, para entendermos sobre as fontes dos conhecimentos bem como sobre as variedades dos conhecimentos e dos seus objetos. O autor assevera que os conhecimentos têm um valor universal e objetivo e que não deve ser atribuída a estes características puramente circunstanciais. Assim, o papel da escola é preservar os conhecimentos por meio do currículo que é um sistema de mensagem organizado sob a forma de disciplinas que estão ligadas à natureza específica de cada campo do conhecimento.

Michael Young, em entrevista dada à Galian e Louzano (2014) em sua passagem pela Universidade de São Paulo, participando como palestrante do II Seminário FEUSP sobre Currículo - Escola e Sociedade do Conhecimento, "expôs sua perspectiva atual sobre o debate teórico em torno do currículo, afirmando a falta de uma sólida teoria do conhecimento que oriente as discussões acerca das escolhas curriculares" (p. 1109). Para Young (2010), educação e conhecimento são inseparáveis. Segundo as autoras do artigo citado, a preocupação de Young,

\footnotetext{
passa a ser a de firma uma posição contrária à defesa de um currículo por resultados, instrumental e imediatista, ressaltando a necessidade de garantir acesso ao conhecimento, em especial para crianças e jovens dos grupos sociais desfavorecidos; defende que a escola não se afaste de sua tarefa específica, disponibilizando o conhecimento especializado, que não se acessa na vida cotidiana e que pode oferecer generalizações e base para se fazer julgamentos, fornecendo parâmetros de compreensão de mundo (GALIAN e LOUZANO, 2014, p. 112).
}

Assim, cada disciplina é um processo de atenção à realidade e exige métodos próprios. Neste sentido, para a manutenção da qualidade da educação integral é imprescindível a preservação da tradição de um currículo disciplinar que garanta a permanência das treze disciplinas que compõem, tradicionalmente, o currículo do ensino médio. 
Young defende que as fronteiras entre as disciplinas são importantes e as disciplinas conferem identidade à escola e aos estudantes. Na defesa de um conhecimento poderoso como sendo papel da escola, o autor acentua que:

\begin{abstract}
o conhecimento poderoso é o conhecimento especializado oriundo dos campos do conhecimento - ou das disciplinas, como as chamamos na escola. Ambos - os campos do conhecimento e as disciplinas - têm limites em torno deles, mas os limites não são estáticos, apenas proveem uma certa estabilidade. Não são, como afirmou Pierre Bourdieu em um de seus primeiros artigos, limites arbitrários. Não significa isso os limites não são arbitrários. Nós organizamos o conhecimento para separar química e física, por exemplo, ou história e geografia, porque descobrimos que podemos entender mais os fenômenos quando estabelecemos esses limites (Idem, p.1118).
\end{abstract}

Mas, a nova legislação educacional brasileira rompe com a tradição disciplinar e justifica, para tanto, que é preciso "romper com a centralidade das disciplinas nos currículos e substituí-las por aspectos mais globalizadores e que abranjam a complexidade das relações existentes entre os ramos da ciência no mundo real" (BRASIL, BNCC, p. 471). No entanto, para se pensar sobre as formas de integração entre as disciplinas tem-se antes que pensar nos conteúdos disciplinares, pois sabemos que para haver interdisciplinar e transdisciplinar é necessário haver a disciplinaridade e respeito a natureza das fronteiras.

Terry Shinn (2020), no texto: Regimes de produção e difusão de ciência: rumo a uma organização transversal do conhecimento, defende a importância da existência das fronteiras, mesmo em um regime transversal e interdisciplinar do conhecimento. De acordo com ele, o regime disciplinar tornou-se totalmente estabelecido durante o século XIX e continua a expandir-se no século XXI (p.15).

Apesar da existência de muita retórica acerca da morte das disciplinas e sua substituição pela interdisciplinaridade (cf. Gibbonset al., 1994; Nowotny et al., 2001) e, freqüentemente, de muito discurso sobre política científica e programação a favor da interdisciplinaridade, a substância e a estabilidade das disciplinas não parecem estar em perigo. (...) Percebe-se aqui que a disciplinaridade parece ir na contramão das demandas mercadológicas. E não favorece a praticidade inerente às demandas econômicas. Ao regime disciplinar não cabe soluções práticas. Assim, a função capital do regime disciplinar não a resolução de problemas práticos (SHINN, 2008, p. 15). 
A natureza do conhecimento é pluralista e um regime de conhecimentos transversal e interdisciplinar deve considerar a importância das fronteiras entre os conhecimentos, e é o reconhecimento dessas fronteiras que possibilita a travessia destas fronteiras. O binômio diferenciação/integração é constituinte da ideia de transversalidade e interdisciplinaridade.

O desprezo à disciplinaridade evidenciado na configuração do novo ensino médio pode ser explicado pela argumentação acima. As disciplinas que sugerem a ênfase no conhecimento em si, não no conhecimento para fazer algo, não atende as demandas mercadológicas preconizadas pelo gerencialismo neoliberal que espera a preparação de jovens aptos para o trabalho, em detrimento da educação de jovens numa visão integral.

Isso não significa que não defendamos modelos de organização curricular que promova um melhor diálogo entre as disciplinas, mas que a natureza das fronteiras disciplinares deve ser respeitada. "As fronteiras claramente persistem, mas estão aqui presentes ótimas condições para a travessia de fronteiras e para a transversalidade" (SHINN, 2008, p. 19). Ou, citando Young, em entrevista concedida:

\begin{abstract}
Não vejo problema algum com o currículo interdisciplinar, desde que, antes, os alunos já tenham tido acesso às disciplinas que compõem o currículo interdisciplinar. Caso contrário, eles não saberão onde estão, ficarão confusos. As disciplinas são a base sobre a qual transmitimos conhecimento para as próximas gerações. Portanto, as disciplinas escolares são sempre contextualizadas a partir dos campos do conhecimento (GALIAN e LOUZANO, 2014, p.1119).
\end{abstract}

Mas, na proposta do novo ensino médio brasileiro o que se vê é um desrespeito à natureza das fronteiras disciplinares e um esvaziamento dos conhecimentos e dos objetivos educacionais. Para construir um currículo rico que consiga traduzir a variedade dos conhecimentos e suas relações é necessária a consideração da epistemologia das fronteiras. 


\section{A conservação como contenção da crise educacional}

A partir da nova legislação do ensino médio é possível notar uma crise na educação brasileira, expressa pela desconsideração da tradição epistemológica seguida há anos, que especifica que os estudantes do ensino médio devam cursar as treze disciplinas que constavam nos currículos, até o novo ensino médio entrar em vigor. Suprimindo, assim, a tradição epistemológica que era pautada na estruturação do currículo por componentes curriculares, o trabalho das professoras e professores carece de sentido e o papel da escola é sublimado, diante da inespecificidade das suas ações educativas.

Ronai Rocha, no livro Quando ninguém educa (2017), apresenta a ideia de que o currículo escolar tem uma função reguladora das atividades escolares, pois regula tanto as atividades docentes quanto dos discentes e da estrutura administrativa da escola. Diz ele:

O currículo é um elemento essencial para que a tarefa de formação humana não seja apenas o resultado aleatório da soma de esforços individuais isolados de cada professor, um lance de dados. Podemos pensar no currículo como ideal regulador (ROCHA, 2017, p. 134).

À vista disso, é através do currículo que definimos os direitos de aprendizagem dos estudantes e este currículo deve conservar a tradição epistemológica. No entanto, a partir do novo ensino médio, vemos ruir a fundamentação que fornece a base para o currículo, que são as disciplinas escolares.

Desta forma, a crise atual no ensino médio no Brasil é decorrente das bruscas mudanças curriculares preconizadas na nova legislação educacional, por apresentarem uma ruptura com a tradição epistemológica vigente - através da diluição dos componentes curriculares em suas respectivas áreas do saber.

Mas, de acordo com Arendt, para conter a crise educacional é necessária uma atitude de conservação. 
Diz Arendt:

\begin{abstract}
penso que o conservadorismo, tomado enquanto conservação, faz parte da essência mesma da actividade educativa cuja tarefa é sempre acarinhar e proteger alguma coisa (...). A própria responsabilidade alargada pelo mundo que a educação assume implica, como é óbvio, uma atitude conservadora (p. 46-47) (...). Hoje é extremamente difícil garantir esse mínimo de conservação e de atitude de conservação sem a qual a educação não é simplesmente possível (ARENDT, 2011, p. 49-50).
\end{abstract}

Embora ouvimos falar muito mal da dimensão conservadora da educação e da sua condição transmissora de conhecimentos, sem a conservação daquilo que há de mais valioso na história do conhecimento humano acumulado não é possível haver uma educação de qualidade. Uma vez que somos responsáveis pelo mundo, devemos proteger o que construímos ao longo da nossa história e garantir que o legado do conhecimento seja transmitido para as novas gerações. Por isso, precisamos de atitudes de conservação para que o papel da escola e da educação não seja rebaixado.

Por conseguinte, evitamos que aconteça o que assevera Ronai Rocha no livro citado acima:

\begin{abstract}
A escola, assim rebaixada, deixou de ser escola. Os conteúdos e as disciplinas foram aos poucos relegados ao sol da boa vontade do professor. As leis, por sua vez, adotaram, grandiloquentes, outra linguagem, e começaram a falar em atividades, áreas do conhecimento, temas transversais e interdisciplinaridade. A perda de objeto foi compensada pelo discurso (ROCHA, 2017, p. 116).
\end{abstract}

Essa citação trata de uma realidade que está próxima a acontecer, se os ditames da nova legislação educacional brasileira entrarem em vigor nas escolas no Brasil, pois de acordo com o que está exposto na legislação, não apenas a educação dos jovens brasileiros será afetada por esta nova legislação, mais a formação profissional docente também será profundamente empobrecida. O currículo que deveria ser um ideal regulador perde os seus alicerces e da educação é retirado o seu chão. 


\section{Considerações Finais}

Este trabalho abordou os principais pontos das mudanças preconizadas pelo novo ensino médio no Brasil, mostrando que o que propõem a nova legislação é realizar uma brusca ruptura com a tradição epistemológica curricular vigente que apresentava o currículo a partir de um modelo disciplinar, através de 13 disciplinas.

Assim, a educação brasileira passa por um momento de crise, uma vez que vemos se concretizar um forte abalo dos alicerces que basilavam a educação brasileira. Mas, sob quais alicerces deve se desenvolver a educação? Os alicerces sob os quais devem se construir o ato educativo, denominam-se componentes curriculares. Deve-se se conservar a tradição disciplinar para a apresentação dos conhecimentos dentro de um currículo, pois é através do currículo que definimos os direitos de aprendizagem dos estudantes.

E, mesmo que as mudanças catastróficas na educação brasileira, no nível médio, já seja uma realidade, as palavras de Hannah Arendt ainda conseguem nos trazer esperanças de dias melhores, pois diz ela: "Pode-se mesmo admitir que se está aqui face a um processo automático, desde que se não esqueça que o pensamento e a ação humanos têm o poder de interromper e fazer parar este processo" (ARENDT, 2011, p. 34).

\section{Referências}

AGUIAR, Márcia Ângela e DOURADO, Luiz Fernandes (Org.). A BNCC na contramão do PNE. Recife: ANPAE, 2018.

ARENDT. Hannah. A crise na educação. In: ARENDT, H. Entre o passado e o futuro. São Paulo: Perspectiva, 2011.

BRASIL. Base Nacional Comum Curricular - Ensino Médio. Brasília: Disponível em: <http://basenacionalcomum.mec.gov.br/bncc-ensino-medio>. Acesso em: 07 dez. 2019.

BRASIL. Diretrizes Curriculares Nacionais para o Ensino Médio. Brasília: Disponível em:

<http://novoensinomedio.mec.gov.br/resources/downloads/pdf/dcnem.pdf>. Acesso em: 04 dez. 2018. 
BRASIL. Lei 13.415. Brasília: Edições Câmara, 2017.

BRASIL. Disponível em: <https://www.congressonacional.leg.br/materias/medidasprovisorias/-/mpv/126992>. Acesso em: 14 fev. 2018.

BRASIL. Lei de Diretrizes e Bases da Educação Nacional, LDB. 9394/1996.

CHERVEL, André. História das disciplinas escolares: reflexões sobre um campo de pesquisa. Porto Alegre: Teoria \& Educação, n. 2, 1990.

GALIAN, Cláudia Valentina Assumpção e LOUZANO, Paula Baptista Jorge. Michael Young e o campo do currículo: da ênfase no "conhecimento dos poderosos" à defesa do "conhecimento Poderoso". Revista Educação e Pesquisa, São Paulo: Vol. $40, n^{\circ} 4$, p. $1108-1124$, out. 2014.

LABAREE, David F. How to succeed in school without really learning. Yale: Yale University Press, 1998.

MACEDO, Elizabeth. Base nacional comum curricular: $A$ falsa oposição entre conhecimento para fazer algo e conhecimento em si. Belo Horizonte: Educação em Revista, v.32, n. 02, junho. 2016.

RAMALHO, Ellen Maianne Santos Melo. Reforma do ensino médio: uma análise da implementação da Lei 13.415/17 nas escolas de Arapiraca. In: Simpósio Internacional de Educação, $9^{\circ}$. Aracajú-SE. Anais. Disponível em:

<https://eventos.set.edu.br/index.php/simeduc/issue/view/19/showToc>. Acesso em: 11 mar. 2020.

ROCHA, Ronai Pires da.Ensino de Filosofia e Currículo. Petrópolis, RJ: Vozes, 2008.

ROCHA, Ronai Pires da. Quando ninguém educa:questionando Paulo Freire. São Paulo: Contexto, 2017.

SHINN, Terry. Regimes de produção e difusão de ciência: rumo a uma organização transversal do conhecimento. Scientiæstudia, São Paulo, v. 6, n. 1, p. 11-42, 2008.

YOUNG, Michael, F. D. Why educators must differentiate knowledge from experience? Journal of the Pacific Circle Consortium for Education, v. 22, n. 1, p. 920, Dez. 2010. 
YOUNG, Michael. O futuro da educação em uma sociedade do conhecimento: o argumento radical em defesa de um currículo centrado em disciplinas. Rio de Janeiro: Rev. Bras. Educ., v. 16, n. 48, p. 609-623, dez. 2011. Disponível em <http://www.scielo.br/scielo.php?script=sci_arttext\&pid=S141324782011000300005\&lng=pt\&nrm=iso>. Acessos em: 04 fev. 2021. https://doi.org/10.1590/S1413-24782011000300005.

YOUNG, Michael. Conhecimento e currículo: do socioconstrutivismo ao realismo social na sociologia da educação. Porto: Porto editora, 2010.

\section{Notas}

${ }^{1}$ Disponível em: <https://www.congressonacional.leg.br/materias/medidas-provisorias/-/mpv/126992>. Acesso em: 14/02/2018.

\section{(c) (i) (2) (2)}

This work is licensed under a Creative Commons Attribution-NonCommercial 4.0 International (CC BY-NC 4.0) 